\title{
Organisational storytelling with cognitive work analysis: Case study of air power doctrine and strategy narrative
}

\author{
$\underline{\text { A. Brady }}^{\mathrm{a}}$, N. Naikar ${ }^{\mathrm{a}}$ and A. Treadwell ${ }^{\mathrm{a}}$ \\ ${ }^{a}$ Centre for Cognitive Work and Safety Analysis, Joint and Operations Analysis Division, Defence Science \\ and Technology Organisation, Melbourne \\ Email: ashleigh.brady2@dsto.defence.gov.au
}

\begin{abstract}
In this paper, a novel application of cognitive work analysis is proposed, specifically that of organisational storytelling. Although cognitive work analysis (Rasmussen, Pejtersen, and Goodstein, 1994; Vicente, 1999) is a reasonably mature framework, having demonstrated its efficacy in relation to a range of systems and applications, its relevance to organisational storytelling has not been investigated before.
\end{abstract}

Organisational storytelling is a strategy for capturing and sharing ideas in a style that makes the ideas more accessible and memorable than conventional communication strategies (Denning, 2005). Stories provide a means for expressing organisational experience, transmitting values, co-creating vision and strategy, and implementing plans and decisions. Current approaches to storytelling rely on the use of powerful examples for effective communication but, despite their potency, examples are insufficient for complex narratives such as that relating to military doctrine and strategy. For such narratives, cognitive work analysis provides a complementary solution.

Cognitive work analysis is a framework for modelling the work demands of complex sociotechnical systems. Its various dimensions provide a strong theoretical lens for examining the distinctions between such concepts as a system's purposes, goals, values, principles, functions, missions, roles, and characteristics, thereby promoting the development of organisational narratives that are logical, rigorous, and coherent. Moreover, work domain analysis, the first dimension, provides a comprehensive characterisation of a system's purposes, values and priorities, functions, and physical resources. As these properties are relevant across many different actors and situations, a work domain model promotes the development of organisational narratives that can encompass the perspectives of multiple stakeholders and evolve over time.

The utility of cognitive work analysis for organisational storytelling may be demonstrated with a case study of its application to inform a narrative of the Royal Australian Air Force's doctrine and strategy. Alongside the general concepts of cognitive work analysis, work domain models of Australia's Air Power and Air Combat systems were important. This framework led to a logical characterisation of the meaning and interrelationships of a variety of air power concepts such as roles (e.g., strike, control of the air), missions (e.g., offensive counter air, strategic attack), and functions (e.g., force application, force protection). It also improved the rigour with which air power concepts are described, preserving clear connections between individual concepts, such as concentration of force, and broader constructs, such as principle of war. Moreover, by establishing a thread in the evolution of air power concepts, the coherence of the narrative was strengthened.

On the basis of this case study, it may be claimed that cognitive work analysis provided a useful means for organisational storytelling, having influenced the narrative of Australian air power doctrine and strategy. Its contribution to this narrative was unique, complementing the conventional operational viewpoint with a strong analytical perspective. Finally, this approach was shown to be feasible, having been achieved within specific schedule, personnel, and financial restrictions.

In sum, this paper extends the application of cognitive work analysis to organisational storytelling. The value of this approach is demonstrated with a case study involving the development of a credible narrative of the Royal Australian Air Force's doctrine and strategy. One limitation of this research is that it relies on a single case study. However, having documented this new application, further case studies are likely. Future research should also explore the suitability of cognitive work analysis for generating different kinds of organisational narratives.

Keywords: Organisational storytelling, cognitive work analysis, work domain analysis, doctrine, strategy 
Brady et al., Organisational storytelling with cognitive work analysis: Case study of air power doctrine and strategy narrative

\section{INTRODUCTION}

This paper presents a novel application of cognitive work analysis (CWA) - that of organisational storytelling. CWA has convincingly demonstrated its relevance for modelling the work demands of a range of systems, including military and process control systems, and for addressing a variety of problems, such as interface design (Burns and Hajdukiewicz, 2004) and team design (Naikar, Pearce, Drumm, and Sanderson, 2003). However, the usefulness and feasibility of CWA for organisational storytelling has not yet been demonstrated.

Organisational storytelling $^{1}$ is a strategy for capturing and communicating new and complex ideas in a form that allows the ideas to be absorbed easily and naturally and makes the ideas memorable (Denning, 2005). It provides a means for expressing organisational experience; confirming shared meaning; developing, sharpening, or renewing a sense of purpose; transmitting values; co-creating vision and strategy; and implementing plans and decisions. Effective storytelling is important for ensuring credibility, both with people internal and external to the organisation. Credible storytelling is critical for inspiring confidence in leaders, engaging and exciting people, igniting action, and securing funds and resources.

Current approaches to storytelling are largely based on the use of powerful examples to communicate specific messages (Denning, 2005). For instance, to convey the idea of the value of knowledge sharing across organisations to staff of the World Bank, Denning related a story of how, in 1995, a health worker in Zambia was able to use an American-based website to learn how to treat malaria. Despite the potency of this approach, examples do not, and cannot, provide the full solution for effective storytelling, especially in the case of more complex narratives such as that required for the communication of military doctrine and strategy. For such narratives, it is proposed that CWA provides a solid foundation for organisational storytelling that complements the use of examples.

\subsection{Military doctrine and strategy}

Military doctrine represents the fundamental principles that guide the employment of military forces. Complementary to doctrine is strategy, a set of purposeful ideas implemented by military forces to pursue desired strategic objectives (Kainikara, 2008). These narratives provide military forces with a common conceptual framework to codify their beliefs, values, and practices, thereby encapsulating a military's overarching aims and missions and the procedures, tactics, and techniques necessary to employ military power successfully. The development of sustainable and effective doctrine and strategy is inherently collaborative, requiring multiple stakeholders, such as key Government and military figures, to reflect the varying goals, functions, and roles within a military organisation. Importantly, doctrine and strategy is evolving and dynamic, being responsive to geopolitical events and technological developments (Sloan, 2012).

\subsection{Cognitive work analysis}

CWA (Rasmussen, Pejtersen, and Goodstein, 1994; Vicente, 1999) is a constraint-based framework for the analysis, design, and evaluation of work in complex sociotechnical systems. Viewing systems as intrinsically work systems, or systems that exist to perform work, it comprises five dimensions that capture different kinds of information about a system's work demands (Figure 1) with specialised modelling tools. By clearly demarcating and describing the fundamental orientations from which a system's work composition may be viewed, this framework provides a rich structure for comprehending a system's abstract or conceptual form, thereby offering a sound basis for generating many kinds of organisational narratives.

Specifically, the CWA framework provides a strong theoretical lens with which to view and comprehend the distinctions between such concepts as a system's purposes, goals, values, principles, functions, missions,

\footnotetext{
${ }^{1}$ Definitions of 'story' and 'narrative' are plentiful. As Denning observes "We all know, or think we know what a story is but when we try to define it, or explain it, then we find our assumptions about it can splinter into a multiplicity of possible meanings" (Denning, 2009, What is a story? Retrieved from http://www.stevedenning.com/Business-Narrative/what-is-a-story.aspx). For this reason, we use the terms 'story' and 'narrative' in the broadest sense as a "telling" (Mackall, 2003, What is narrative, anyway? Retrieved from http://www.poynter.org/how-tos/newsgathering-storytelling/chip-on-your-shoulder/16324/what-is-narrative-anyway/) or as "anything told or recounted" (Denning, 2009, What is a story? What is narrative meaning? http://www.stevedenning.com/BusinessNarrative/definitions-of-story-and-narrative.aspx). We subscribe to the view of Pulitzer Prize winning reporter, Mark Fritz, that a story or narrative "is merely a thread that combines words and facts in a way that keeps the reader reading" (Fritz, 2003, What is narrative, anyway? Retrieved from http://www.poynter.org/how-tos/newsgathering-storytelling/chip-on-your-shoulder/16324/what-is-narrativeanyway/) or a listener listening. This thread is often based on causal connections, or temporal connections, between events-but not always - as Denning acknowledges (Denning, 2009, What is a story? What is narrative meaning? Retrieved from http://www.stevedenning.com/Business-Narrative/definitions-of-story-and-narrative.aspx).
} 
Brady et al., Organisational storytelling with cognitive work analysis: Case study of air power doctrine and strategy narrative

roles, and characteristics. For example, the framework clearly distinguishes the concepts of purposes and goals, representing these in different dimensions of analysis. While goals are dynamic and may vary as a function of the situation, a system's purposes are more stable over time (Burns and Vicente, 2001; Naikar, 2013). Similarly, the framework maintains a strict distinction between the concepts of functions and activities, also treating these in separate analytic dimensions (Naikar, 2013; Vicente, 1999). Whereas functions represent the utility of objects or devices independently of actions, activities can involve sequences of actions for achieving specific goals. Finally, the concepts of values and principles also may be differentiated based on the CWA framework. Values represent abstract concepts of what is right, worthwhile, or desirable, while principles reflect fundamental truths that can be used as a basis for conduct. Understanding a system's fundamental operating concepts from this well-founded analytical perspective promotes the development of organisational narratives that are logical, rigorous, and coherent.

The individual dimensions of CWA also provide robust foundations for compelling organisational storytelling. Central to the case study presented in this paper is work domain analysis, the first dimension. This dimension provides a comprehensive description of a system that links its purposes to its physical resources via a series of interconnected levels of abstraction (Naikar, 2013; Rasmussen et al., 1994; Vicente, 1999). At the top of the hierarchy

\begin{tabular}{|l|l|}
\hline \multicolumn{1}{|c|}{ Dimensions } & \multicolumn{1}{c|}{ Kinds of Information } \\
\hline Work Domain Analysis & $\begin{array}{l}\text { Purposes, values \& priorities, } \\
\text { functions \& physical resources }\end{array}$ \\
\hline Activity Analysis & $\begin{array}{l}\text { What work needs to be done in } \\
\text { a system }\end{array}$ \\
\hline Strategies Analysis & $\begin{array}{l}\text { Ways that the work can be } \\
\text { performed }\end{array}$ \\
\hline $\begin{array}{l}\text { Social Organisation and } \\
\text { Cooperation Analysis }\end{array}$ & $\begin{array}{l}\text { Who can carry out the work and } \\
\text { how it can be shared }\end{array}$ \\
\hline $\begin{array}{l}\text { Worker Competencies } \\
\text { Analysis }\end{array}$ & $\begin{array}{l}\text { Competencies required by } \\
\text { workers }\end{array}$ \\
\hline
\end{tabular}

(Figure 2), the functional purposes level represents the objectives of a system and the external limits placed on its operation. This level reveals the fundamental reasons for a system's existence. At the value and priority measures level, the criteria that must be respected for a system to achieve its functional purposes are portrayed. These criteria comprise fundamental laws, principles, or values. The third level, purpose-related functions, describes those functions a system must be capable of supporting to achieve its higher-order objectives. Lastly, the bottom two levels capture the physical resources of a system: the object-related processes level presents the functional processes or functional capabilities or limitations of physical objects, while the last level depicts those physical objects.

The links in the abstraction hierarchy denote structural means-ends relations, with the term 'structure' used to mean relatively permanent. Nodes at lower levels identify the structural means for achieving the nodes at higher levels. Conversely, nodes at higher levels define the structural ends for which the nodes at lower levels are necessary.

By providing a detailed system description that is relatively permanent - or constant across many different actors and situations-work domain analysis leads to an in-depth understanding of the principal constraints on a system's operation: the purposes it must fulfil, the values and priorities it must preserve, the functions it must be able to perform, and the physical resources it must possess in order to fulfil its functions, values and priorities, and purposes. As these constraints do not vary as a function of specific actors, a work domain model promotes the development of organisational narratives that can encompass the perspectives of multiple stakeholders. Moreover, as these constraints remain relatively stable across situations, a work domain model allows organisational narratives to evolve over time to suit the challenges of the changing environment, while remaining true to the system's intrinsic work demands, such that the narratives are enduring.

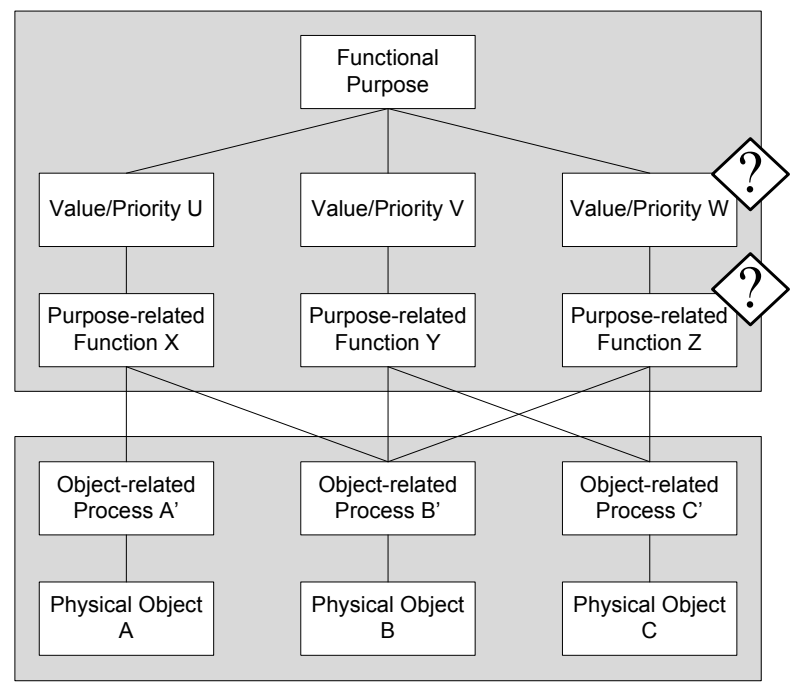

Figure 2. A generic abstraction hierarchy (Reproduced from Naikar, 2013). 
Brady et al., Organisational storytelling with cognitive work analysis: Case study of air power doctrine and strategy narrative

\section{CASE STUDY}

This section presents a case study of the application of CWA to the Royal Australian Air Force's (RAAF) doctrine and strategy. The aim of this work was to contribute to the development of a credible organisational narrative for communicating air power doctrine and strategy to a broad target audience, including Australian Air Force and Defence Force personnel, allied and coalition partners, and members of the wider community. The narrative would be published as the forthcoming edition of the Air Power Manual - the Air Force's foundational strategic-level doctrine text. This work was undertaken for the Air Power Development Centre, which resides within the RAAF.

For this application, the broader concepts of CWA, as specified in the Introduction, were utilised. In addition, two work domain models were particularly relevant - one of Australia's Air Power system and the other a more focused analysis of the Air Combat system (Treadwell and Naikar, 2013). For simplicity, this case study focuses on the work domain model of Air Power.

\subsection{Work domain analysis of Air Power}

The work domain analysis of the Air Power system was conducted following a methodology specified by Naikar (2013). This methodology comprises several themes, which include establishing the purposes and boundaries of the analysis, identifying the sources of information, and constructing and validating the work domain model. As the focus of this paper is on the model's application, rather than its construction, only the purposes, boundaries, and information sources will be outlined briefly before a sample of the model is presented.

The general aim of the work domain analysis of the Air Power system was to assist the RAAF in achieving their current and future (2030-2050) capability objectives. A specific application of the model was identified as doctrine development, with the intention being to use the model to contribute sound information about the system's purposes, values and priorities, functions, and physical resources. However, there are many other potential applications of the model, such as organisational design (Naikar, 2012).

The boundaries of the analysis concentrate on Australia's Air Power system. The analysis is limited to military capability and does not include civilian air power. Military air power incorporates the air capabilities of the three armed Services-Air Force, Army, and Navy-with these capabilities including both airborne and ground-based physical entities.

The work domain model of Air Power was developed through extensive document analysis. The sources consulted included a range of Air Force, Defence, Government, and public documents relating to air power doctrine (e.g., the existing Air Power Manual), strategy and policy (e.g., the current Defence White Paper), operating and training procedures (e.g., concepts of operations), and capabilities (e.g., Defence intranet and external websites). Although many of these documents were specific to the Australian context, texts examining basic air power concepts in other contexts were also analysed.

To produce an abstraction hierarchy of the Air Power system, an abstraction-decomposition space was constructed to identify the levels of abstraction and decomposition at which the system would be modelled (Figure 3). This representation shows that the system was modelled according to the five levels of abstraction described earlier and at three levels of decomposition, namely entire system, subsystems, and components. The subsystems and components encompass the combat, transport, intelligence, surveillance, and reconnaissance concerns of the Air Force, among others. The grey shading indicates those cells that were populated with constraints to create the abstraction hierarchy of the Air Power system.

\begin{tabular}{|c|c|c|c|}
\hline & Entire System & Subsystems & Components \\
\hline $\begin{array}{l}\text { Functional } \\
\text { Purposes }\end{array}$ & $\begin{array}{l}\text { Functional purposes of } \\
\text { the entire system }\end{array}$ & $\begin{array}{l}\text { Functional purposes of the } \\
\text { subsystems }\end{array}$ & $\begin{array}{l}\text { Functional purposes of the } \\
\text { components }\end{array}$ \\
\hline $\begin{array}{l}\text { Value and } \\
\text { Priority } \\
\text { Measures }\end{array}$ & $\begin{array}{l}\text { Value and priority } \\
\text { measures of the entire } \\
\text { system }\end{array}$ & $\begin{array}{l}\text { Value and priority } \\
\text { measures of the } \\
\text { subsystems }\end{array}$ & $\begin{array}{l}\text { Value and priority } \\
\text { measures of the } \\
\text { components }\end{array}$ \\
\hline $\begin{array}{l}\text { Purpose-related } \\
\text { Functions }\end{array}$ & $\begin{array}{l}\text { Purpose-related } \\
\text { functions of the entire } \\
\text { system }\end{array}$ & $\begin{array}{l}\text { Purpose-related } \\
\text { functions of the } \\
\text { subsystems }\end{array}$ & $\begin{array}{l}\text { Purpose-related } \\
\text { functions of the } \\
\text { components }\end{array}$ \\
\hline $\begin{array}{l}\text { Object-related } \\
\text { Processes }\end{array}$ & $\begin{array}{l}\text { Object-related } \\
\text { processes of the entire } \\
\text { system }\end{array}$ & $\begin{array}{l}\text { Object-related } \\
\text { processes of the } \\
\text { subsystems }\end{array}$ & $\begin{array}{l}\text { Object-related } \\
\text { processes of the } \\
\text { components }\end{array}$ \\
\hline $\begin{array}{l}\text { Physical } \\
\text { Objects }\end{array}$ & $\begin{array}{l}\text { Physical form of the entire } \\
\text { system }\end{array}$ & $\begin{array}{l}\text { Physical form of the } \\
\text { subsystems }\end{array}$ & $\begin{array}{l}\text { Physical form of the } \\
\text { components }\end{array}$ \\
\hline
\end{tabular}

Figure 3. Air Power abstraction-decomposition space. 
Brady et al., Organisational storytelling with cognitive work analysis: Case study of air power doctrine and strategy narrative

Figure 4 presents a sample of the abstraction hierarchy of Air Power, focusing on some of the nodes at the functional purposes and purpose-related functions levels. The first level demonstrates that the fundamental purpose of the system is to secure Australia and its interests from threats by providing the ability to exploit the air and space for manoeuvre, while respecting the nation's unique constraints. To achieve this purpose, the system must have the capacity to perform a range of functions, with a sample for the

To secure Australia and its interests from threats by providing the ability to exploit the earth's atmosphere and space for manoeuvre, including for the application of lethal force when necessary, given the nation's unique geographical, population, economic, ethical, and legal constraints.

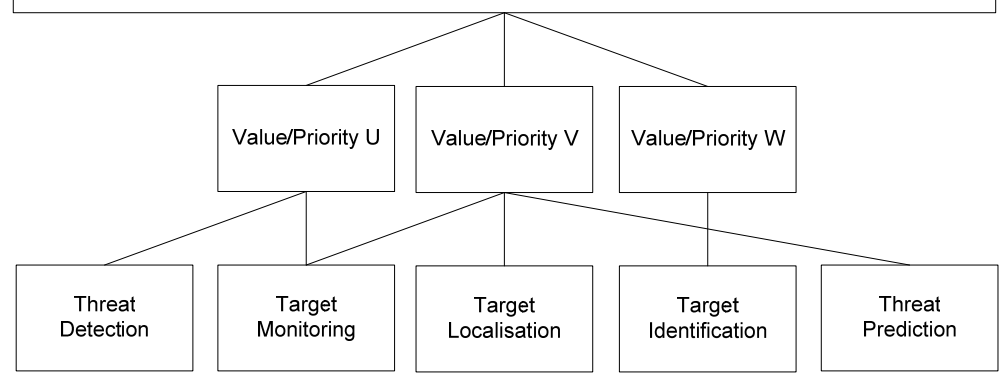

Figure 4. A sample of the Air Power abstraction hierarchy. intelligence, surveillance, and reconnaissance concerns of the Air Force encompassing the detection of threats, the monitoring, localisation, and identification of targets, and the prediction of threats.

Figure 5 portrays the purpose-related functions in the sample abstraction hierarchy in more depth, illustrating the comprehensiveness with which nodes in the model are characterised. The underlined terms are further defined in a glossary. The glossary also provides a detailed explanation of the rationale behind the inclusion of specific nodes and structural means-ends relations in the model.

\subsection{Doctrine and strategy formulation}

The application of $\mathrm{CWA}^{2}$ to doctrine and strategy formulation resulted in a more credible narrative or story of air power. Specifically, this framework provided a basis for refining the logic, rigour, coherence, consistency, and accessibility with which air power doctrine and strategy are presented in the forthcoming edition of the Air Power Manual. The resulting narrative could accommodate the perspectives of multiple stakeholders as well as the evolution in air power concepts since the previous edition of the Air Power Manual. An examination of some of these forms of contribution, illustrated with specific examples, is

\begin{tabular}{|l|l|}
\hline $\begin{array}{c}\text { Purpose-related } \\
\text { Functions }\end{array}$ & \multicolumn{1}{c|}{ Definitions } \\
\hline Threat Detection & $\begin{array}{l}\text { The ability of the Air Power system to establish the presence of } \\
\text { targets with the potential to inflict harm on friendly assets and/or } \\
\text { the civilian population and its infrastructure. }\end{array}$ \\
\hline Target Monitoring & $\begin{array}{l}\text { The ability of the Air Power system to survey the activities of } \\
\text { specified targets. }\end{array}$ \\
\hline Target Localisation & $\begin{array}{l}\text { The ability of the Air Power system to determine the exact } \\
\text { location of specified targets. }\end{array}$ \\
\hline Target Identification & $\begin{array}{l}\text { The ability of the Air Power system to establish the class and } \\
\text { identity of specified targets. }\end{array}$ \\
\hline Threat Prediction & $\begin{array}{l}\text { The ability of the Air Power system to predict the intentions of } \\
\text { specified targets. }\end{array}$ \\
\hline
\end{tabular}
provided below.

Figure 5. A sample of the Air Power purpose-related functions.

The CWA framework promoted a logical characterisation of air power doctrine and strategy. Specifically, it offered a systematic basis for examining the meaning and interrelationships of a variety of air power concepts such as roles (e.g., strike), characteristics (e.g., precision), missions (e.g., offensive counter air), and functions (e.g., force application). As a result, it was possible to identify confusing, overlapping, and circular descriptions of these concepts in existing conceptualisations and, subsequently, develop sound characterisations of each concept. As an example, one outcome of this work was that the set of concepts that had previously been identified as air power characteristics was altered. By incorporating this information into the Air Power Manual, the logical underpinnings of the document could be considerably strengthened.

The rigour with which air power concepts are described could also be improved on the basis of CWA. Specifically, individual concepts like 'concentration of force', 'perspective', and 'strike', were refined to reflect their nature as elements of wider fundamental concepts, in this case the broader constructs of 'principle of war', 'air power characteristic', and 'air power role', respectively. For example, in alignment with Defence doctrine, principles are considered as guides to action or conduct. Accordingly, descriptions of

\footnotetext{
${ }^{2}$ From here on, the term 'CWA' is used to encompass the broader concepts of the framework, as described in the Introduction, and the work domain models of Air Power and Air Combat.
} 
Brady et al., Organisational storytelling with cognitive work analysis: Case study of air power doctrine and strategy narrative

the various elements of the principles of war must be in a form that provides a basis for conduct. The CWA framework made it possible to derive a clear understanding of the connections between individual concepts and broader fundamental concepts and thus recommend how these concepts should be described and presented to ensure rigour in communicating air power doctrine and strategy.

CWA also provided a foundation for formulating a coherent narrative of air power. For example, it was possible to clarify the similarities and distinctions between contemporary concepts of air power (e.g., centralised control and decentralised execution) and enduring concepts of air power and wider defence doctrine (e.g., flexibility). Based on this work, explanations or descriptions of the linkages between concepts were either introduced or refined in existing accounts of doctrine and strategy to develop a coherent story of air power. These contributions were important for signalling to the audience how, why, and in what directions Air Force thinking had evolved over time, thereby establishing continuity - and thus credibilitythrough explicit acknowledgment of the recasting of the air power story.

\subsection{Impact}

The question of whether CWA provided a useful approach for doctrine and strategy formulation can be established on the basis of its impact or ability to influence practice (Naikar, 2013). In the case of the current application, two main demonstrations of impact were evident. The first was that approximately ninety percent of the recommendations provided to the Air Power Development Centre for the development of the forthcoming edition of the Air Power Manual were adopted. The weight of this contribution is further emphasised by the fact that approximately 150 significant issues were raised; numerous minor issues were also identified. The second demonstration of impact was the specific feedback provided by four staff of the Air Power Development Centre. This feedback, which aligns with the forms of contribution discussed in the preceding section, substantiated the positive influence of the CWA framework on air power doctrine and strategy formulation. In addition, the feedback highlighted several other kinds of contribution that were achieved with CWA.

It should be noted that, for practical reasons, not all of our recommendations for doctrine and strategy refinement could be adopted. Furthermore, as a result of input from other stakeholders, reasonably substantial changes were made to the Air Power Manual subsequent to our involvement. Staff members from the Air Power Development Centre conveyed that the Air Power Manual would have benefitted from further input from us following the contributions from other stakeholders, but this was not possible because of time constraints. Nevertheless, for the first application of CWA to doctrine and strategy formulation, reasonable outcomes were achieved with the forthcoming edition of the Air Power Manual. More robust narratives of doctrine and strategy may be developed with succeeding applications of the framework.

\subsection{Uniqueness}

Another basis for judging the usefulness of CWA for doctrine and strategy formulation is with regard to its uniqueness relative to standard techniques (Naikar, 2013). Conventional approaches have typically focused on developing military doctrine and strategy from an operational standpoint. While there is no question that this position is central to the exercise, the necessity of involving multiple stakeholders from the military community - to cover the full spectrum of relevant concepts - tends to result in articulations of doctrine and strategy that are limited by the challenges of integrating several distinct, yet overlapping, perspectives.

The CWA framework complements the operational approach to doctrine and strategy development by contributing a scientifically-driven analytical approach. As outlined earlier, this framework provides a sound theoretical basis with which to distinguish such concepts as a system's purposes, goals, values, principles, functions, missions, roles, and characteristics. Moreover, the work domain analysis dimension provides a comprehensive characterisation of a system's fundamental constraints. This model, which is independent of specific actors or situations, provides a robust foundation for integrating multiple stakeholders' perspectives into a single narrative and allowing a narrative to evolve over time. These and other features of CWA promote the development of organisational narratives that are logical, rigorous, and coherent and-for these reasons-credible.

\subsection{Feasibility}

The feasibility of CWA for doctrine and strategy formulation may be established on the basis of whether this approach can be accomplished within the schedule, personnel, and financial constraints of a project (Naikar, 2013). The current application was achieved within these limits. The contributions to doctrine and strategy were made over a five-month period. Existing work domain models of Australia's Air Power and Air Combat 
Brady et al., Organisational storytelling with cognitive work analysis: Case study of air power doctrine and strategy narrative

systems, coupled with deep and extensive knowledge of the CWA framework, enabled these contributions to be achieved at short notice and within tight timeframes. This work was performed by three researchers, who could contribute the majority of their time to this project. The main financial cost stemmed from their wages.

\section{DISCUSSION AND CONCLUSIONS}

This paper has presented a novel application of CWA to organisational storytelling. The value of this approach was demonstrated with a case study involving the development of a credible organisational narrative of the RAAF's doctrine and strategy. The utility of CWA for this problem was established on the basis of its impact, uniqueness, and feasibility.

As a single case was employed to investigate the efficacy of CWA for organisational storytelling, it is difficult to conclude with certainty that the results of the current study are reliable. However, by documenting this new application of CWA, this paper will facilitate successive case studies. Consequently, it will become possible to establish whether CWA consistently provides a useful and feasible approach for developing organisational narratives.

Future research should explore the use of CWA for other forms of organisational storytelling. By expanding this approach to encompass other types of communication challenges, the full worth of CWA for developing organisational narratives can be determined.

\section{ACKNOWLEDGEMENTS}

We are grateful to: Group Captain Mark Hinchcliffe, Wing Commander David Holder, Dr Sanu Kainikara, and Lieutenant Colonel Ken Bailey from the Air Power Development Centre for the opportunity to contribute to the forthcoming Air Power Manual; Air Commodore Mike Bennett, former Director General Strategy and Planning, Air Force Headquarters, for sponsoring the development of the work domain models of Air Power and Air Combat; Dr Seng Boey, our Task Leader, for his oversight of our work; Ella Duckworth, Sandra Lambeth, and Jenny Yeung for their earlier contributions to the work domain model of Air Power; and Elissa Scuderi for her research assistance.

\section{REFERENCES}

Burns, C. M., and Hajdukiewicz, J. R. (2004). Ecological interface design. Boca Raton, FL: CRC Press.

Burns, C. M., and Vicente, K. J. (2001). Model-based approaches for analysing cognitive work: A comparison of abstraction hierarchy, multilevel flow modeling, and decision ladder modeling. International Journal of Cognitive Ergonomics, 5(3), 357-366.

Denning, S. (2005). The leader's guide to storytelling: Mastering the art and discipline of business narrative. San Francisco, CA: John Wiley \& Sons, Inc.

Kainikara, S. (2008). A fresh look at air power doctrine. Tuggeranong, ACT: Air Power Development Centre.

Naikar, N. (2012). Cognitive work analysis: Foundations, extensions, and challenges. DSTO General Document (DSTO-GD-0680). Fishermans Bend, Australia: Defence Science and Technology Organisation.

Naikar, N. (2013). Work domain analysis: Concepts, guidelines, and cases. Boca Raton, FL: Taylor \& Francis Group, LLC.

Naikar, N., Pearce, B., Drumm, D., and Sanderson, P. M. (2003). Designing teams for first-of-a-kind, complex systems using the initial phases of cognitive work analysis: Case study. Human Factors, 45(2), 202217.

Rasmussen, J., Pejtersen, A. M., and Goodstein, L. P. (1994). Cognitive systems engineering. New York: John Wiley \& Sons.

Sloan, G. (2012). Military doctrine, command philosophy and the generation of fighting power: Genesis and theory. International Affairs, 88(2), 243-263.

Treadwell, A., and Naikar, N. (2013). The application of work domain analysis to defining Australia's air combat capability. Manuscript submitted for publication.

Vicente, K. J. (1999). Cognitive work analysis: Toward safe, productive, and healthy computer-based work. Mahwah, NJ: Lawrence Erlbaum Associates. 